\title{
Influence of Fiber Shape and Water-Binder Ratio on Blast Resistance of PVA Fiber Reinforced Mortar
}

\author{
Danny Triputra SETIAMANAH ${ }^{1, a^{*}}$, Makoto YAMAGUCHI ${ }^{1, b}$, Priyo SUPROBO ${ }^{2, \mathrm{c}}$, \\ Shintaro MORISHIMA ${ }^{1, d}$, Zicheng ZHANG $^{1, e}$, \\ Atsuhisa OGAWA ${ }^{3, f}$ and Takashi KATAYAMA ${ }^{3,9}$ \\ ${ }^{1}$ 2-39-1, Kurokami, Chuo-ku, Kumamoto-shi, Kumamoto 860-8555, JAPAN \\ ${ }^{2}$ Raya ITS, Keputih, Sukolilo, Surabaya, East Java 60111, INDONESIA \\ ${ }^{3}$ Ote Center Bldg., 1-1-3, Otemachi, Chiyoda-ku, Tokyo, 100-8115, Japan \\ a176d8938@st.kumamoto-u.ac.jp, byamaguchi@arch.kumamoto-u.ac.jp, cpriyo@ce.its.ac.id, \\ d184d9261@st.kumamoto-u.ac.jp, e'172d8912@st.kumamoto-u.ac.jp,

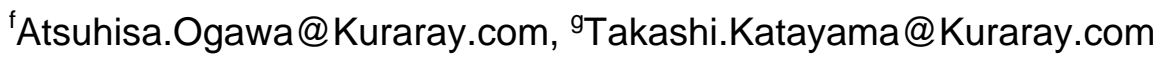

Keywords: Fiber Reinforced Mortar, Contact Detonation, Local Failure, Fiber Shape, Water-Binder Ratio

\begin{abstract}
Reducing spall damage is a major problem when designing blast-resistant concrete structures. This study was conducted to evaluate the influence of various material factors on the blast resistance of FRCC slabs under contact detonation. The contact detonation tests were carried out on polyvinyl alcohol fiber reinforced mortar (PVAFRM) slabs with four different shapes of PVA fibers and four different water-binder ratios (W/B) of the mortar matrix. Fly ash (type II) was used as admixture and the fluidity of the PVAFRM in its fresh state was varied using a superplasticizer and thickener. As a result, it was obtained that longer fiber is more effective to suppress spall if the fiber diameter is constant, and if the aspect ratio of fiber (lf/df) is constant, finer fibers are more effective to reduce spall. Moreover, the spall-reducing performance is reduced when the W/B value is too high or too low, and it is considered that there is an appropriate value of W/B that depends on the fiber shape.
\end{abstract}

\section{Introduction}

When designing blast-resistant concrete structures, reducing spall damage is a major problem. Spalling indicates the failure of reinforced concrete (RC) slabs due to contact detonation which caused by the tensile stress waves reflected from the backside of the slab. To preserve human life under such circumstances, the launch of concrete fragments accompanies the spalling needs to be prevented. The authors have verified the good spall-reducing performance of fiber reinforced cementitious composite (FRCC) slabs under contact detonation ${ }^{1)}$. However, a designing method for obtaining the required blast-resistant performance of the FRCC members has not been developed yet; one of the reasons for this is that it is difficult to obtain dynamic mechanical properties of FRCCs corresponding to this problem where the dominant strain rate is of the order of $10^{3}-10^{4} / \mathrm{s}$. Hence, it may be convenient to consider the spall-reducing performance of FRCC member as a material property of the FRCC. It can be obtained directly based on material factors such as fiber shape, water-binder ratio, and so on.

This study was conducted to evaluate the influence of various material factors on the blast resistance of FRCC slabs under contact detonation; therefore, contact detonation tests were carried out on polyvinyl alcohol fiber reinforced mortar (PVAFRM) slabs with four different shapes of PVA fibers and four different water-binder ratios of the mortar matrix. 
Table 1 Materials used for PVAFRM.

\begin{tabular}{|l|l|}
\hline Cement & Ordinary Portland cement; Density: $3.16 \mathrm{~g} / \mathrm{cm}^{3}$ \\
\hline Admixture & Fly ash (Type II); Density: $2.27 \mathrm{~g} / \mathrm{cm}^{3}$, Specific surface area: $3890 \mathrm{~cm}^{2} / \mathrm{g}$ \\
\hline Fine aggregate & Mountain sand; Surface-dried density: $2.56 \mathrm{~g} / \mathrm{cm}^{3}$, Water absorption: $2.29 \%$, \\
& Maximum size: $2.5 \mathrm{~mm}$, Fineness modulus: 2.58 \\
\hline Chemical admixture & Superplasticizer (Polycarboxylic-acid type); Thickener (Methylcellulose type) \\
\hline Short fibers & PVA fiber (Type I); Density: $1.30 \mathrm{~g} / \mathrm{cm}^{3}$, Dimension: $\phi 0.1 \times 12 \mathrm{~mm}$, \\
& Tensile strength: $1200 \mathrm{MPa}$, Tensile elastic modulus: $28 \mathrm{GPa}$ \\
& PVA fiber (Type II); Density: $1.30 \mathrm{~g} / \mathrm{cm}^{3}$, Dimension: $\phi 0.2 \times 12 \mathrm{~mm}$, \\
& Tensile strength: $975 \mathrm{MPa}$, Tensile elastic modulus: $27 \mathrm{GPa}$ \\
& PVA fiber (Type III); Density: $1.30 \mathrm{~g} / \mathrm{cm}^{3}$, Dimension: $\phi 0.2 \times 18 \mathrm{~mm}$, \\
& Tensile strength: $975 \mathrm{MPa}$, Tensile elastic modulus: $27 \mathrm{GPa}$ \\
& PVA fiber (Type IV); Density: $1.30 \mathrm{~g} / \mathrm{cm}^{3}$, Dimension: $\phi 0.2 \times 24 \mathrm{~mm}$, \\
& Tensile strength: $975 \mathrm{MPa}$, Tensile elastic modulus: $27 \mathrm{GPa}$ \\
\hline
\end{tabular}

Table 2 Mixture proportions and static mechanical properties of PVAFRM.

\begin{tabular}{|c|c|c|c|c|c|c|c|c|c|c|c|c|c|c|c|c|c|}
\hline \multirow{2}{*}{$\begin{array}{l}\text { Fiber } \\
\text { type }\end{array}$} & \multirow{2}{*}{$\begin{array}{c}V_{\mathrm{f}} \\
{[\%]}\end{array}$} & \multirow{2}{*}{$\begin{array}{l}\mathrm{W} / \mathrm{B} \\
{[\%]}\end{array}$} & \multirow{2}{*}{$\begin{array}{c}\mathrm{FA} / \mathrm{B} \\
{[\%]}\end{array}$} & \multirow{2}{*}{$\begin{array}{l}\text { S/B } \\
{[\%]}\end{array}$} & \multicolumn{5}{|c|}{ Unit weight $\left[\mathrm{kg} / \mathrm{m}^{3}\right]$} & \multirow{2}{*}{$\begin{array}{c}\mathrm{Sp} / \mathrm{B} \\
{[\%]}\end{array}$} & \multirow{2}{*}{ Flow } & \multirow{2}{*}{$\begin{array}{c}\gamma \\
{\left[\mathrm{kN} / \mathrm{m}^{3}\right]}\end{array}$} & \multirow{2}{*}{$\begin{array}{c}\sigma_{\mathrm{B}} \\
{[\mathrm{MPa}}\end{array}$} & \multirow{2}{*}{$\begin{array}{c}E \\
{[\mathrm{GPa}]}\end{array}$} & \multirow{2}{*}{$\begin{array}{l}\varepsilon_{\mathrm{co}} \\
{[\mu]}\end{array}$} & \multirow{2}{*}{$\begin{array}{c}\sigma_{\mathrm{f}} \\
{[\mathrm{MPa}]}\end{array}$} & \multirow{2}{*}{$\begin{array}{c}\bar{\sigma}_{\mathrm{b}} \\
{[\mathrm{MPa}}\end{array}$} \\
\hline & & & & & $\mathrm{C}$ & FA & $\mathrm{W}$ & $S$ & V & & & & & & & & \\
\hline \multirow[t]{4}{*}{ I } & 2.0 & 50 & 20 & 100 & 649 & 162 & 406 & 812 & 0.5 & 0 & 205 & \begin{tabular}{|l|}
18.7 \\
\end{tabular} & 35.2 & 14.4 & \begin{tabular}{|l|}
4670 \\
\end{tabular} & \begin{tabular}{|l|}
5.93 \\
\end{tabular} & 5.02 \\
\hline & 2.0 & 40 & 20 & 100 & 707 & 177 & 353 & 883 & 0 & 0 & 155 & 20. & 7.5 & 0.4 & 5350 & 6.13 & 5.09 \\
\hline & 2.0 & 33 & 20 & 100 & 753 & 188 & 311 & 942 & 0 & 0.6 & 177 & 19. & 57.4 & 20.7 & 4380 & 7.07 & 5.12 \\
\hline & 2.0 & 25 & 20 & 100 & 815 & 204 & 255 & 1018 & 0 & 1.7 & 197 & 21.8 & 89.9 & 29.1 & 44480 & 9.70 & 7.24 \\
\hline \multirow[t]{4}{*}{ II } & 2.0 & 50 & 20 & 100 & 649 & 162 & 406 & 812 & 0.5 & 0 & 257 & 19.4 & 39.2 & 15.8 & 4600 & 3.58 & 3.17 \\
\hline & 2.0 & 40 & 20 & 100 & 707 & 177 & 353 & 883 & 0 & 0 & 212 & 20.6 & 61.0 & 20.1 & 5570 & 8.26 & 6.51 \\
\hline & 2.0 & 33 & 20 & 100 & 753 & 188 & 311 & 942 & 0 & 0.5 & 217 & 20.9 & 73.5 & 23.6 & 5000 & 8.80 & 6.22 \\
\hline & 2.0 & 25 & 20 & 100 & 815 & 204 & 255 & 1018 & 0 & 1.7 & 290 & 2.2 & 93.4 & 31.0 & 4150 & 7.69 & 6.00 \\
\hline \multirow[t]{4}{*}{ III } & 2.0 & 50 & 20 & 100 & 649 & 162 & 406 & 812 & 0.5 & 0 & 238 & 19.3 & 37.3 & 15.5 & \begin{tabular}{|l|l}
4470 \\
\end{tabular} & 6.28 & 5.22 \\
\hline & 2.0 & 40 & 20 & 100 & 707 & 177 & 353 & 883 & 0 & 0 & 212 & 20.6 & 57.6 & 19.7 & 4860 & 7.50 & 6.19 \\
\hline & 2.0 & 33 & 20 & 100 & 753 & 188 & 311 & 942 & 0 & 0.5 & 215 & 19.5 & 57.8 & 20.8 & 4150 & 7.38 & 5.94 \\
\hline & 2.0 & 25 & 20 & 100 & 815 & 204 & 255 & 1018 & 0 & 1.7 & 249 & 22.2 & 96.6 & 30.3 & 4620 & 9.90 & 8.16 \\
\hline \multirow[t]{4}{*}{ IV } & 2.0 & 50 & 20 & 100 & 649 & 162 & 406 & \begin{tabular}{|l|}
812 \\
\end{tabular} & 0.5 & 0 & 231 & 19.2 & 37.1 & 15.2 & \begin{tabular}{|l|}
44670 \\
\end{tabular} & 5.78 & 4.71 \\
\hline & 2.0 & 40 & 20 & 100 & 707 & 177 & 353 & 883 & 0 & 0 & 190 & 20.6 & 57.0 & 18.1 & 5140 & 9.15 & 7.81 \\
\hline & 2.0 & 33 & 20 & 100 & 753 & 188 & 311 & 942 & 0 & 0.5 & 191 & 21.1 & 74.5 & 24.5 & 4730 & 10.1 & 7.05 \\
\hline & 2.0 & 25 & 20 & 100 & 815 & 204 & 255 & 1018 & 0 & 1.7 & 260 & 22.2 & 92.8 & 28.3 & 5040 & \begin{tabular}{|l|}
11.3 \\
\end{tabular} & 9.52 \\
\hline
\end{tabular}

Notes; $\mathrm{V}_{\mathrm{f}}$ : fiber volume fraction, $\mathrm{C}$ : cement, FA: fly ash, $\mathrm{B}(=\mathrm{C}+\mathrm{FA})$ : binder, $\mathrm{W}$ : water, $\mathrm{S}$ : sand, V: thickener, Sp: superplasticizer, $\gamma$ : air-dried density, $\sigma_{\mathrm{B}}$ : compressive strength, E: Young's modulus, $\varepsilon_{\mathrm{co}}$ : strain at compressive strength, $\sigma_{\mathrm{f}}$ : flexural strength, and $\bar{\sigma}_{\mathrm{b}}$ : flexural toughness coefficient.

\section{Materials}

Table 1 lists the materials used for PVAFRM. The PVA fibers with the following shapes were employed: type I was $\phi 0.1 \times 12 \mathrm{~mm}$ (Aspect ratio (lf/df): 120); type II was $\phi 0.2 \times 12 \mathrm{~mm}(\mathrm{lf} / \mathrm{d} f=$ $60)$; type III was $\phi 0.2 \times 18 \mathrm{~mm}(l f / d f=90)$ and; type IV was $\phi 0.2 \times 24 \mathrm{~mm}(l f / d f=120)$. To provide high fluidity to PVAFRM in its fresh state, fly ash (type II) was used as admixture.

Table 2 lists the mixture proportions of the PVAFRM. The water-binder ratio $(W / B)$ varied over the values $25,33,40$, and $50 \%$ with the fiber volume fraction, replacement ratio of cement by fly ash, and sand-binder ratio fixed at 2.0, 20, and 100\%, respectively. The fluidity of the PVAFRM in its fresh state was varied using a superplasticizer and thickener. The static mechanical properties of various PVAFRMs are shown in Table 2.

\section{Specimens Configuration}

All the specimens were $500 \mathrm{~mm}$ long, $500 \mathrm{~mm}$ wide, and $80 \mathrm{~mm}$ thick, as shown in Fig. 1. It was investigated that the influence of the steel reinforcement on the local failure is negligible [2]; 


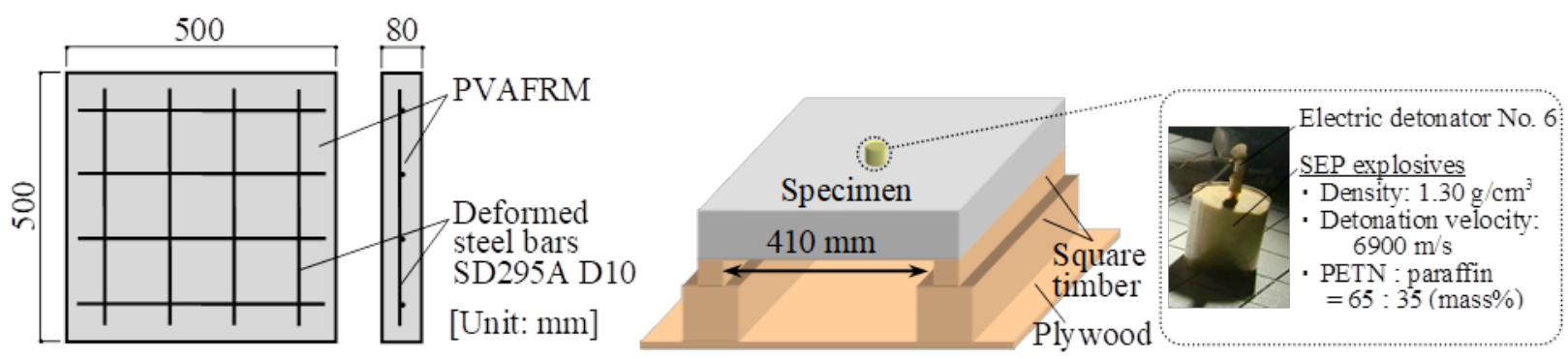

Fig. 1 Configuration ad bar-arrangement of speciment. Fig. 2 Test set-up for contact detonation.

Table 3 Failure modes of PVAFRM specimens.

\begin{tabular}{|c|c|c|c|c|c|}
\hline & \multicolumn{4}{|c|}{ Aspect ratio of PVA fiber } \\
\hline & & $\begin{array}{c}60 \\
\left(\mathrm{~d}_{\mathrm{f}}=0.2 \mathrm{~mm},\right. \\
\text { Type II })\end{array}$ & $\begin{array}{c}90 \\
\left(\mathrm{~d}_{\mathrm{f}}=0.2 \mathrm{~mm},\right. \\
\text { Type III })\end{array}$ & $\begin{array}{c}120 \\
\left(\mathrm{~d}_{\mathrm{f}}=0.2 \mathrm{~mm},\right. \\
\text { Type IV })\end{array}$ & $\begin{array}{c}120 \\
\left(\mathrm{~d}_{\mathrm{f}}=0.1 \mathrm{~mm},\right. \\
\text { Type } \mathrm{I})\end{array}$ \\
\hline \multirow{4}{*}{$\begin{array}{l}W / B \\
{[\%]}\end{array}$} & 50 & Spall & Spall & Spall & Crater \\
\hline & 40 & Spall & Spall & Spall & Crater \\
\hline & 33 & Spall & Crater & Crater & Crater \\
\hline & 25 & Spall & Spall & Spall & Crater \\
\hline
\end{tabular}

however, lattice-like rebars with the horizontal and vertical intervals $120 \mathrm{~mm}$ in the center of slab thickness were employed to prevent the cracking of the slab.The PVAFRM was placed so that the casting surface became the blasted surface. These specimens were cured in water at $20{ }^{\circ} \mathrm{C}$ for 28 days, and then cured in air for 14 days until testing.

The specimen was supported by two wooden jigs with an inside span of $410 \mathrm{~mm}$, as shown in Fig. 2. The SEP explosives were installed in the center of the upper surface of the specimen and blasted using an electric detonator No. 6. The amount of explosives is $70 \mathrm{~g}$, which corresponds to the breach limit of a normal concrete slab with a thickness of $80 \mathrm{~mm}^{2}$.

\section{Fracture appearances}

Tables 3 and 4 show the failure modes and the fracture appearances of the PVAFRM specimens, respectively. The following results can be obtained from these tables:

(a) Spall was prevented at $W / B=33 \%$ in types III and IV, whereas spall occurred at all $W / B$ value in type II. Therefore, although it depends on $W / B$ value, it is more effective to adapt longer fibers to suppress spall if the fiber diameter is constant; this may be because long fibers are difficult to be pull out.

(b) Spall was suppressed at all $W / B$ value in type I, but spall occurred at $W / B=50,40$, and $25 \%$ in type IV. Therefore, it is more effective to adapt finer fibers to suppress spall if the $l_{f} / d_{f}$ value is constant. By analogy from the previous finding that rebar reinforcement hardly affects the spall failure $^{2)}$, the reinforcing level becomes macroscopic by using thick-diameter fibers so that the effect of suppressing embrittlement of spall failure spot caused by dense cracks may be reduced.

(c) For types III and IV, spall was suppressed at $W / B=33 \%$, but occurred at $W / B=50,40$, and $25 \%$. Therefore, the spall-suppressing performance is reduced when the $W / B$ value is too high or too low; it is considered that there is an appropriate value of $W / B$ that depends on the fiber shape. In general, the lower the $W / B$ value, the greater the bond strength at the fiber-matrix interface so that fiber pull-out is less likely to occur. On the contrary, as the $W / B$ value increases, the pressure rise may be alleviated by the plastic compaction, which is a phenomenon in which the pressure rise is relieved by crushing the voids in the porous material. It is considered that the value of $W / B$ is appropriate when the above two effects are balanced. As shown in Fig. 3, fine spall-fragments tend to increase in a low W/B mixture; the fiber-reinforcing effect may be reduced because the matrix was broken into small pieces by a strong inflation pressure. 
Table 4 Fracture appearances of PVAFRM specimens subjected to contact detonation.

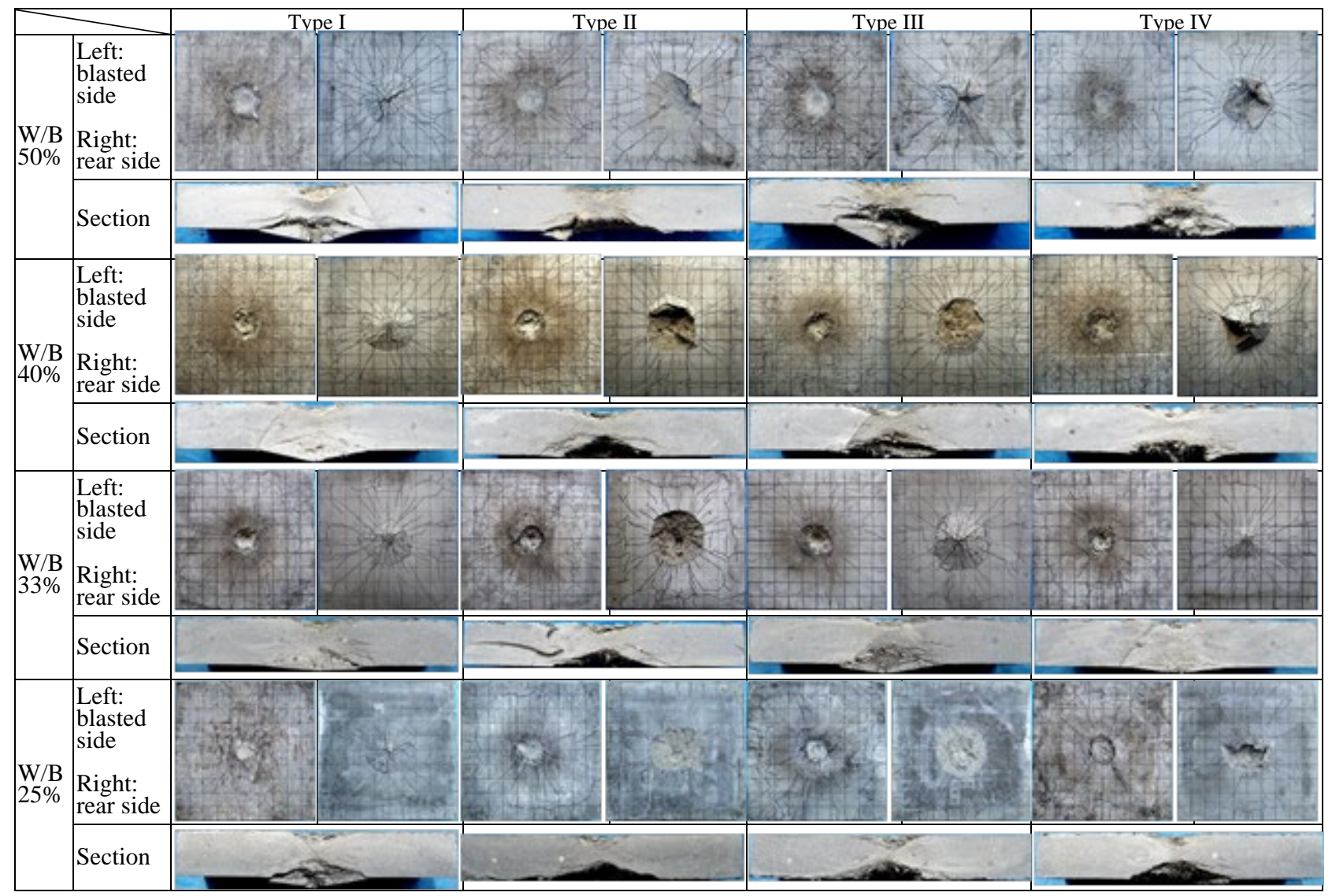

Notes; Each specimen was supported on both the left and right sides. The visible cracks that occurred on the blasted and rear sides were emphasized.

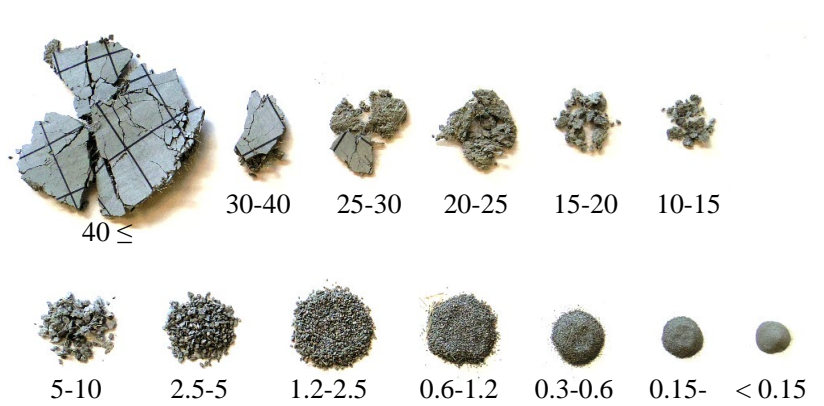

(a) PVAFRM with type III fiber (W/B=40\%)
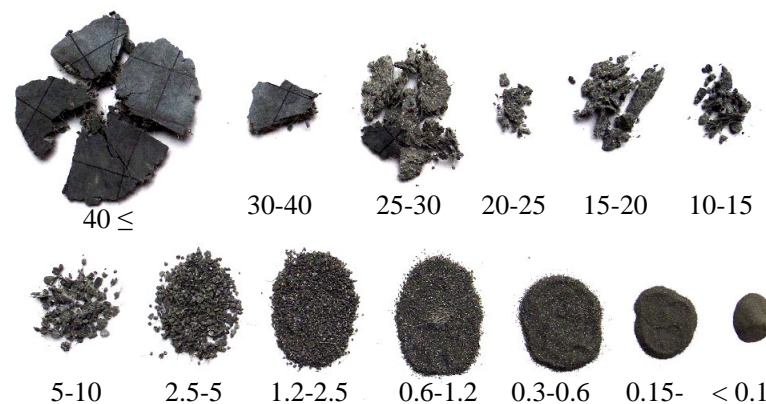

1.2-2.5

0.6-1.2
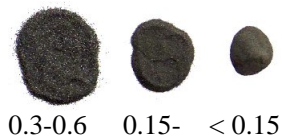

(b) PVAFRM with type III fiber (W/B=25\%)

[Unit: mm]

\section{Local failure size}

Fig. 3 Examples of appearances of spall-fragments.

Figures 4 to 7 show the influences of $l_{f} / d_{f}$ and $W / B$ values on the local failure sizes. In these figures, the calculations by the equations for estimating the local failure sizes in a normal concrete slabs ${ }^{2)}$ are also shown.

As shown in Fig. 4, the crater diameter is almost constant regardless of the fiber shape, but the crater diameter tends to decrease with the decrease in $W / B$ value. In the problem of contact detonation, it is expected that part of mortar at the crater portion will be extruded toward its outer peripheral part. According to this experimental results, because the bond at the fiber-matrix is strengthened as the $W / B$ value decreases, the embrittlement of the outer periphery of the crater may 
be suppressed. However, the relationship between the crater diameter and the $W / B$ value is not linear; the reducing effect tends to be moderate as the $W / B$ value decreases.

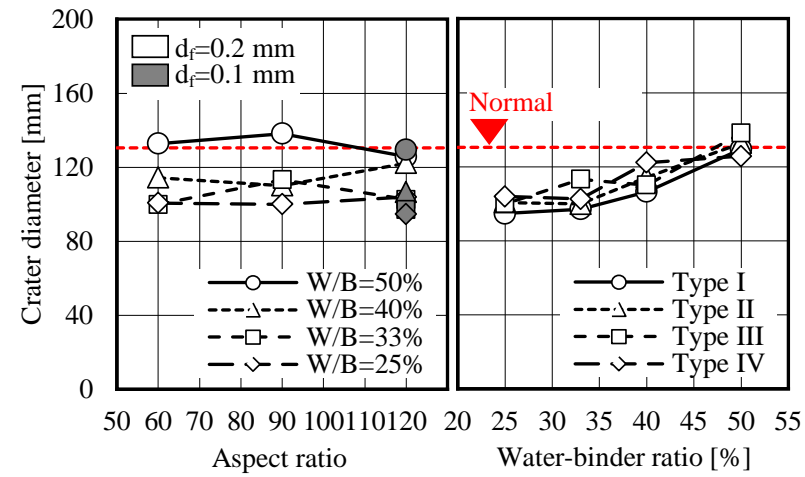

Fig. 4 Influence of $\mathrm{l}_{\mathrm{f}} / \mathrm{d}_{\mathrm{f}}$ and $\mathrm{W} / \mathrm{B}$ on crater diameter.

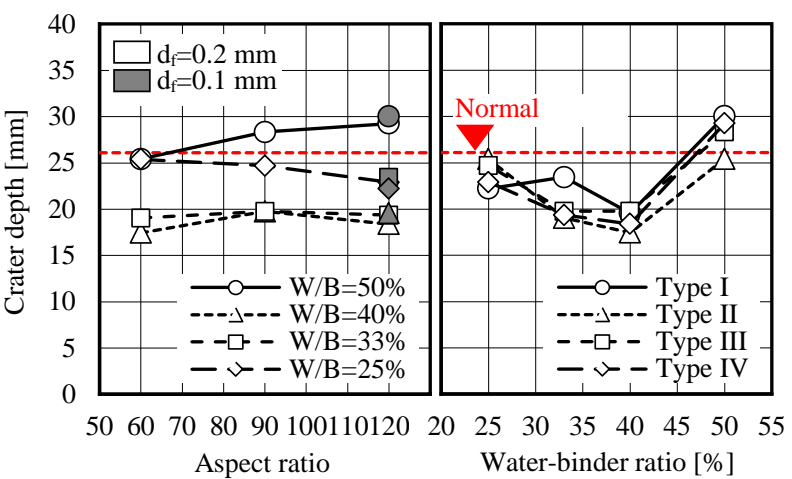

Fig. 5 Influence of $\mathrm{l}_{\mathrm{f}} / \mathrm{d}_{\mathrm{f}}$ and $\mathrm{W} / \mathrm{B}$ on crater depth.

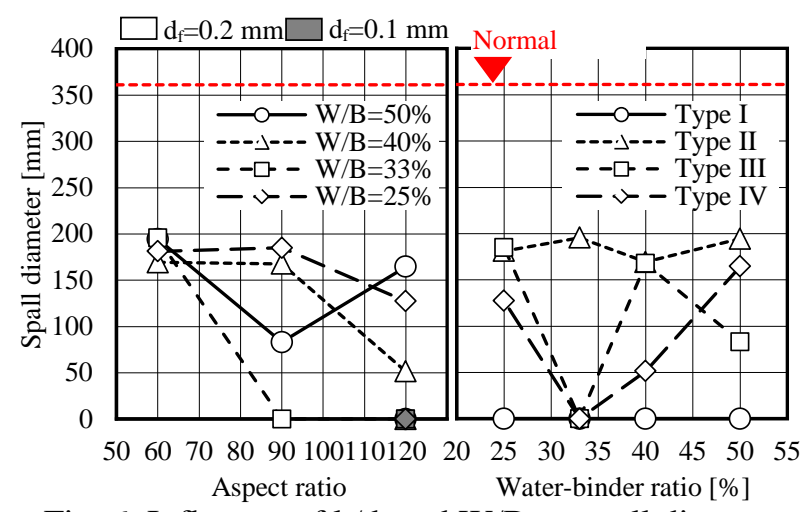

Fig. 6 Influence of $\mathrm{l}_{\mathrm{f}} / \mathrm{d}_{\mathrm{f}}$ and $\mathrm{W} / \mathrm{B}$ on spall diameter.

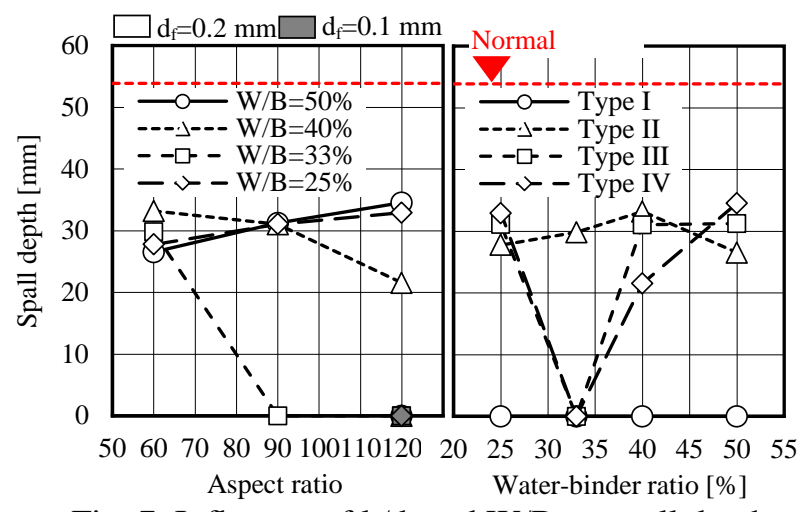

Fig. 7 Influence of $\mathrm{l}_{\mathrm{f}} / \mathrm{d}_{\mathrm{f}}$ and $\mathrm{W} / \mathrm{B}$ on spall depth.

On the other hand, it can be seen from Fig. 5 that the relationship between the crater depth and the $W / B$ value is different from the above: the crater depth reaches a minimum value at $W / B=40 \%$. This may be because the crater bottom tends to be crushed due to the above-mentioned plastic compaction when $W / B=50 \%$; conversely, in the range where $W / B$ value is $33 \%$ or less, because the plastic compaction effect is weakened with a decrease in $W / B$ value, the crater bottom tends to be broken brittlely. Therefore, when the $W / B$ value is higher or lower than its appropriate value, the spall occurs and the crater depth also increases, suggesting a risk that the breach easily occurs.

From Fig. 6, although the spall diameter is somewhat dispersed, it tends to be generally reduced as the fiber length increases, and no definite correlation with $W / B$ value is observed. In addition, as shown in Fig. 7, the spall depth was within the range of $30 \pm 4 \mathrm{~mm}$ in nine mixtures among ten mixtures in which spall occurred.

\section{Influences of fiber}

In general, it is known that fibers in FRCC tend to be two-dimensionally oriented in a plane parallel to the casting surface, except for the parts that are forcibly oriented by a formwork and so on. Therefore, it is predicted that the volume of fibers bridging the side part of the spall failure surface is high, and the volume of fibers bridging the top part is relatively less, as shown in Fig. 8 (a). As a result, the fibers bridging the side of the spall failure surface and the flexural cracking surface inside the spall-fragments mainly contribute to the prevention of spall (Fig. 8 (b)), and spall occurs when the bridging force is lost (Fig. 8 (c)). 


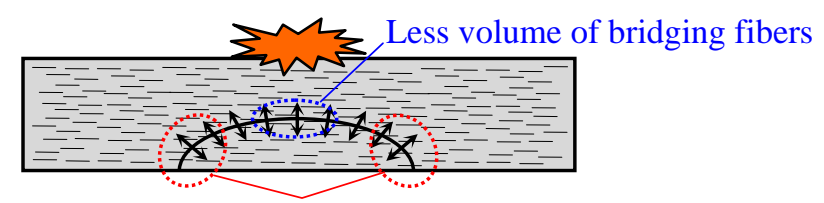

High volume of bridging fibers

(a) Fiber orientation inside the PVAFRM.

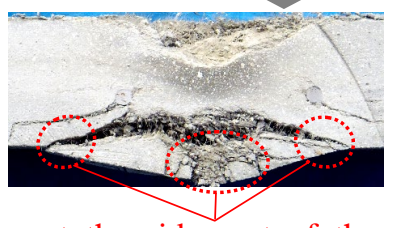

Fibers bridging at the side part of the spall failure surface and the flexural cracks inside the spall-fragments may contribute to the prevention of spall.

(b) Spall is suppressed.

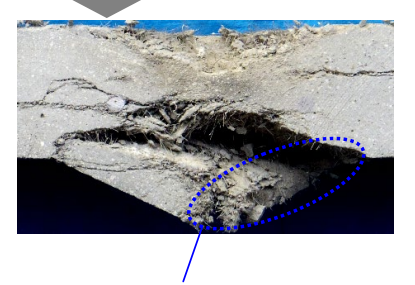

When the bridging force of fibers referred in (b) is lost, the spall may occur.

(c) Spall occurs.

Fig. 8 Schematic image for influence of fiber

By analogy from the previous finding that concrete strength hardly affects the spall dimensions ${ }^{2}$, it is expected that the position of the spall failure surface is almost invariable regardless of the matrix strength; therefore, it is considered that the spall depth of the specimen in which the spall occurred became almost constant irrespective of the difference in the $W / B$ value.

\section{Conclusion}

The following conclusions were reached:

1) It is more effective to adapt longer fibers to suppress spall if the fiber diameter is constant. Further, if the $l_{f} / d_{f}$ value is constant, it is more effective to adapt finer fibers to suppress spall.

2) The spall-suppressing performance is reduced when the $W / B$ value is too high or too low, and it is considered that there is an appropriate value of $W / B$ that depends on the fiber shape.

3) Although the crater diameter is reduced with the decrease in the $W / B$ value, the optimum $W / B$ value is attained when the crater depth reaches its minimum value.

4) In the specimens in which the spall occurred, the spall depth became almost constant even when the $l_{f} / d_{f}$ and $W / B$ values differed; this is possibility owing to the influence of the fiber orientation.

\section{Acknowledgements}

The contact detonation tests were carried out at the explosion laboratory of the Institute of Pulsed Power Science of Kumamoto University. The authors sincerely appreciate the help of Prof. K. Hokamoto, Assoc. Prof. N. Kawai, Assist. Prof. S. Tanaka, technical staff Y. Toda and A. Hamasaki, assistant technical staff T. Kusano, and students T. Ohmi, K. Gotoh, and K. Takasaki. The authors would also like to thank Kyuden Sangyo Co., Inc. and Shin-Etsu Chemical Co., Ltd. for their cooperation in conducting the experiments. This work was supported by JSPS KAKENHI (Grant-in-Aid for Scientific Research (C), Grant Number: 17K00647, Principal Investigator: M. Yamaguchi).

\section{References}

[1] M. Yamaguchi et al.: Blast Resistance of Polyethylene Fiber Reinforced Concrete to Contact Detonation, Journal of Advanced Concrete Technology, 9(1), pp.63-71, 2011. https://doi.org/10.3151/jact.9.63

[2] M. Morishita et al.: Effects of Concrete Strength and Reinforcing Clear Distance on the Damage of Reinforced Concrete Slabs Subjected to Contact Detonation, Concrete Research and Technology, 15(2), pp.89-98, 2004. https://doi.org/10.3151/crt1990.15.2_89 